\title{
Identification of type VI collagen synthesizing cells in human diabetic glomerulosclerosis using renal biopsy sections*
}

\author{
Mohammed Shawkat Razzaque ${ }^{\mathrm{a}, * *}$, Takehiko Koji ${ }^{\mathrm{b}}$, Takashi Harada ${ }^{\mathrm{c}}$ and Takashi Taguchi ${ }^{\mathrm{a}}$ \\ ${ }^{\mathrm{a}}$ Second Department of Pathology, ${ }^{\mathrm{b}}$ Third Department of Anatomy, ${ }^{\mathrm{c}}$ Second Department of Medicine, \\ Nagasaki University School of Medicine, Nagasaki, Japan
}

\begin{abstract}
Although the role of extracellular matrices in the development of glomerulosclerosis has been discussed widely, the cellular origin of type VI collagen in diabetic nephropathy (DN) has remained relatively unexplored. This study reports the distribution and cellular origin of type VI collagen in DN. Type VI collagen-specific oligonucleotide probes and monoclonal antibody were used to assess the relative expression of mRNA for $\alpha 1$ (VI) chain and its translated protein in paraffin-embedded renal biopsy sections of DN. By immunohistochemistry, compared to the control, increased deposition of type VI collagen was noted in the diffuse and nodular lesions of diabetic glomeruli. For cellular localization of type VI collagen mRNA, paraffin-embedded renal sections of the control and DN were hybridized in situ with digoxigenin (Dig)labeled antisense oligo-DNA probe complementary to a part of $\alpha 1$ (VI) mRNA. In comparison to the control kidney sections, increased numbers of intraglomerular cells (both mesangial and epithelial cells) were positive for $\alpha 1$ (VI) mRNA in renal biopsy sections of DN. From the results, we conclude that overexpression of type VI collagen by intraglomerular cells with its increased deposition might significantly contribute to the glomerulosclerosis found in DN.
\end{abstract}

Keywords: Type VI collagen, diabetic nephropathy, immunohistochemistry, in situ hybridization

\section{Introduction}

Diabetes mellitus (DM) is associated with multiple connective tissue changes, including generalized thickening of basement membranes. About $40 \%$ of DM patients develop nephropathy [3]. In diabetic nephropathy (DN), increased accumulation of extracellular matrix (ECM) results in diffuse and nodular glomerulosclerosis. As the origin and the source of all the components of the ECM in DN has not yet been clearly understood, the identification of ECM producing cells is critical for a better understanding of the sclerotic process in DN. Several components of ECM including type III and type IV collagens have been intensively studied in DN and other renal diseases [7,14,15,17]. We have also reported increased deposition of type III and type IV collagens and their enhanced synthesis in

\footnotetext{
${ }^{*}$ Part of this study was presented in 13th International Congress of Nephrology, held in Madrid, Spain, 1995.

${ }^{* *}$ Address of correspondence: M.S. Razzaque, Second Department of Pathology, Nagasaki University School of Medicine, 1-12-4, Sakamoto, Nagasaki 852, Japan. E-mail: razzaque@ net.nagasaki-u.ac.jp.
} 
diabetic glomerulosclerosis [16]. A few reports demonstrating distribution of type VI collagen in DN are found [12]. However, no report concerning the identification of cells synthesizing this collagen in human renal tissue has been found hitherto. In an attempt to further elucidate the composition of sclerotic matrix in diabetic glomeruli, we investigated the distribution of type VI collagen and its cellular origin in renal tissues biopsied from the patients with DN.

\section{Materials and methods}

\subsection{Kidney tissue}

Renal biopsies from 15 patients with DM, with typical histologic changes of $\mathrm{DN}$ as described in the WHO classification of glomerular diseases [6], and 5 samples of renal tissue obtained in conjunction with renal surgery without any noticeable histological abnormality were used in this study as control. The renal biopsy tissue was processed for routine light and electron microscopic examinations. For the light microscopy, the tissue was fixed in $10 \%$ formalin and embedded in paraffin and were routinely processed by various staining methods, including hematoxylin-eosin (HE), periodic acid schiff (PAS), periodic acid schiff methenamine silver (PAM) and Masson's trichrome to examine the histological alterations. For the electron microscopy, the tissue was fixed in $2.5 \%$ glutaraldehyde, osmicated and embedded in Epon. The antigenic markers for $\operatorname{IgG}, \operatorname{IgA}, \operatorname{IgM}, \mathrm{C} 3$ and $\mathrm{C} 1 \mathrm{q}$ were also examined on the other portions of renal tissue section by immunofluorescence microscopy.

\subsection{Immunohistochemistry}

Paraffin sections $(4 \mu \mathrm{m})$ were deparaffinized and endogenous peroxidase activity was blocked with $0.3 \%$ hydrogen peroxide in methanol $(30 \mathrm{~min})$. After mild treatment with trypsin, the sections were reacted with goat serum to block nonspecific binding of monoclonal antibody (20 min). As immunohistochemical control, monoclonal antibody was substituted by either 0.01 M PBS or mouse IgG diluted with PBS (similar concentration as that of primary antibody). Monoclonal antibody against type VI collagen was purchased from Fuji Chemical and was diluted to $1: 50$ with PBS (pH 7.2). The sections were reacted with the primary antibody $(1 \mathrm{~h})$ and processed further by streptavidin-biotin method using Histofine SAB kit (Nichirei, Tokyo). The staining intensity of type VI collagen was graded semiquantitatively according to the following scale: $(0)=$ no staining, $(+)=$ weak staining, $(++)=$ moderate staining, $(+++)=$ strong staining .

\subsection{In situ hybridization (ISH)}

Oligo-DNA probes used: For ISH, digoxigenin (Dig)-labeled synthetic oligo-DNAs were used as probes. A sequence complementary to mRNA of human pro $\alpha 1$ (VI) chain (382-426) [5] was chosen to locate type VI collagen mRNA-positive cells. A computer-assisted search (GenBank) of the above antisense sequence as well as that of sense sequence revealed no significant homology with any of the known sequences other than that of pro $\alpha 1$ (VI) chain. The oligo-DNAs were synthesized by an automatic DNA synthesizer.

Labeling of oligo-DNAs by digoxigenin: The oligo-DNAs were labeled at their 3 '-end with Dig using digoxigenin tail labeling kit as recommended by Boehringer Mannheim. The digoxigenin labeling of the probes were verified immunochemically on nitrocellulose filter using anti-Dig antibody (Boehringer Mannheim). 
Dot blot hybridization: The hybridizabilities of the Dig-labeled oligo-DNA probes were confirmed by dot blot hybridization as reported [8,15]. Briefly, various amounts $(1 \mathrm{pg}-10 \mathrm{ng} / \mathrm{spot})$ of sense $\alpha 1$ (VI) oligo-DNA was fixed into two nitrocellulose filters and were hybridized with Dig-labeled sense and antisense $\alpha 1$ (VI) oligo-DNAs. The hybrids were detected immunochemically using antiDig antibody.

Experimental procedure: ISH was carried out in selected sections as previously described $[8,17]$. Briefly deparaffinized sections $(4 \mu \mathrm{m})$ were treated with $0.3 \% \mathrm{H}_{2} \mathrm{O}_{2}(30 \mathrm{~min}), 0.2 \mathrm{~N} \mathrm{HCl}(20 \mathrm{~min})$, $0.2 \%$ Triton X-100 $(10 \mathrm{~min})$ and proteinase $\mathrm{K}\left(10 \mu \mathrm{g} / \mathrm{ml} ; 37^{\circ} \mathrm{C} ; 15 \mathrm{~min}\right)$, successively. The sections were post-fixed with $4 \%$ paraformaldehyde (PFA) in PBS (5 min), immersed in $2 \mathrm{mg} / \mathrm{ml}$ glycine (30 $\mathrm{min}$ ) and kept in 40\% deionized formamide in $4 \times$ SSC until used. Overnight hybridization was performed at $37^{\circ} \mathrm{C}$ with $4 \mu \mathrm{g} / \mathrm{ml}$ Dig-labeled antisense oligo-DNA probe in the hybridization solution $[8,16,17]$. Then the slides were washed in $50 \%$ formamide in $2 \times$ SSC and $0.5 \%$ SSC, $2 \times$ SSC and PBS, successively. The sections were reacted with blocking solution $(5 \% \mathrm{BSA}, 500 \mu \mathrm{g} / \mathrm{ml}$ normal sheep IgG, $100 \mu \mathrm{g} / \mathrm{ml}$ salmon testicular DNA and $100 \mu \mathrm{g} / \mathrm{ml}$ yeast tRNA in PBS) for $1 \mathrm{~h}$ and reacted for $15-17 \mathrm{~h}$ with HRP-sheep anti Dig $(1: 200)$ diluted with the blocking solution. The sections were washed four times with $0.075 \%$ Brij 35 in PBS (15 min each), and the sites of peroxidase were visualized using a solution containing 3,3'-Diaminobenzidine/4 $\mathrm{HCl}$ (DAB), $\mathrm{H}_{2} \mathrm{O}_{2}$, Cobalt and Nickel [2] and counterstained by periodic acid schiff (PAS) [16].

Control experiments: The following control experiments were performed to verify the specificity of the hybridization signals: (1) Serial sections were reacted with the hybridization solution containing Dig-labeled sense oligo-DNA probe or hybridization solution without probe. (2) Some consecutive sections were pretreated with RNase-A $\left(100 \mu \mathrm{g} / \mathrm{ml} ; 37^{\circ} \mathrm{C} ; 1 \mathrm{~h}\right)$ before post fixation. (3) Adjacent sections were hybridized with a solution containing a 50-fold excess of non-labeled antisense oligoDNA probe in addition to the Dig-labeled anti-sense oligo-DNA probe.

\section{Results}

\subsection{Localization of type VI collagen by immunohistochemistry}

Type VI collagen was predominantly present in the mesangium (+) and glomerular basement membrane (GBM) (+) of the control glomeruli (Fig. 1A). Compared to the control glomeruli, increased immunostaining (+++) for type VI collagen was recorded in nodular and diffuse lesions of the glomeruli in DN (Fig. 1B). In the late stage of glomerulosclerosis, i.e., in globally sclerotic glomeruli, immunostaining for type VI collagen was slightly lower than earlier stages of glomerulosclerosis, although the collagen distributed diffusely in the sclerotic matrix (Fig. 1C).

\subsection{Detection of Dig-labeled pro $\alpha 1$ (VI) oligo-DNA hybridized on nitrocellulose filter by immunochemistry}

When Dig-labeled antisense pro $\alpha 1$ (VI) oligo-DNA was hybridized with unlabeled sense pro $\alpha 1$ (VI) oligo-DNA on nitrocellulose filter, at least $10 \mathrm{pg}$ of the sense oligo-DNA was detected on nitrocellulose filter. No hybridization signals were found when Dig-labeled sense pro $\alpha 1$ (VI) oligoDNA was hybridized with unlabeled sense pro $\alpha 1$ (VI) oligo-DNA on nitrocellulose filter (data not shown). 

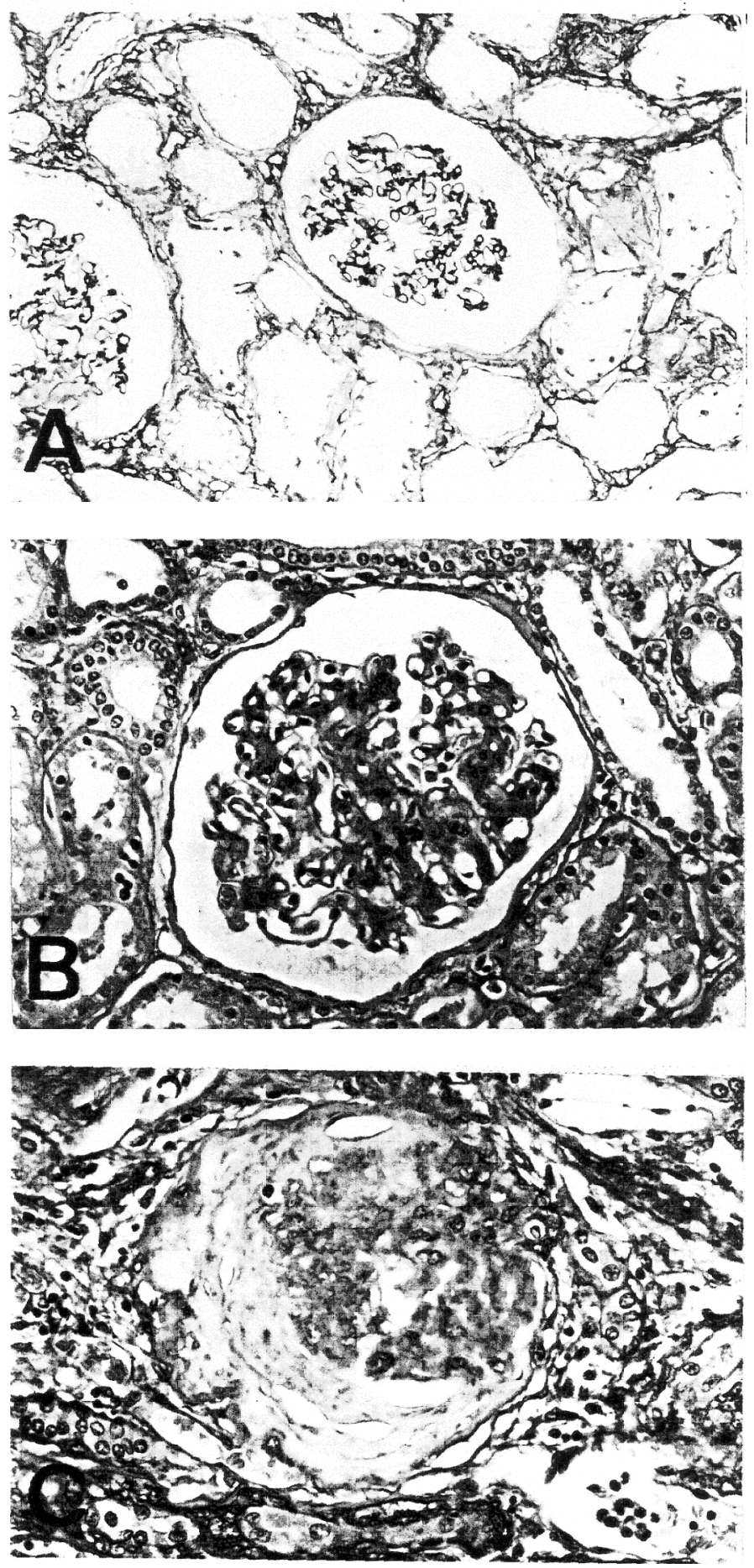

Fig. 1. Immunohistochemical staining of type VI collagens in a control glomerulus (A), showing weak staining in the mesangium, GBM and Bowman's capsule. Note strong immunostaining for type VI collagen in the diffuse sclerotic lesion of a diabetic glomerulus (B) and moderate immunostaining in the late stage of a globally sclerotic glomerulus (C) (immunoperoxidase technique). 

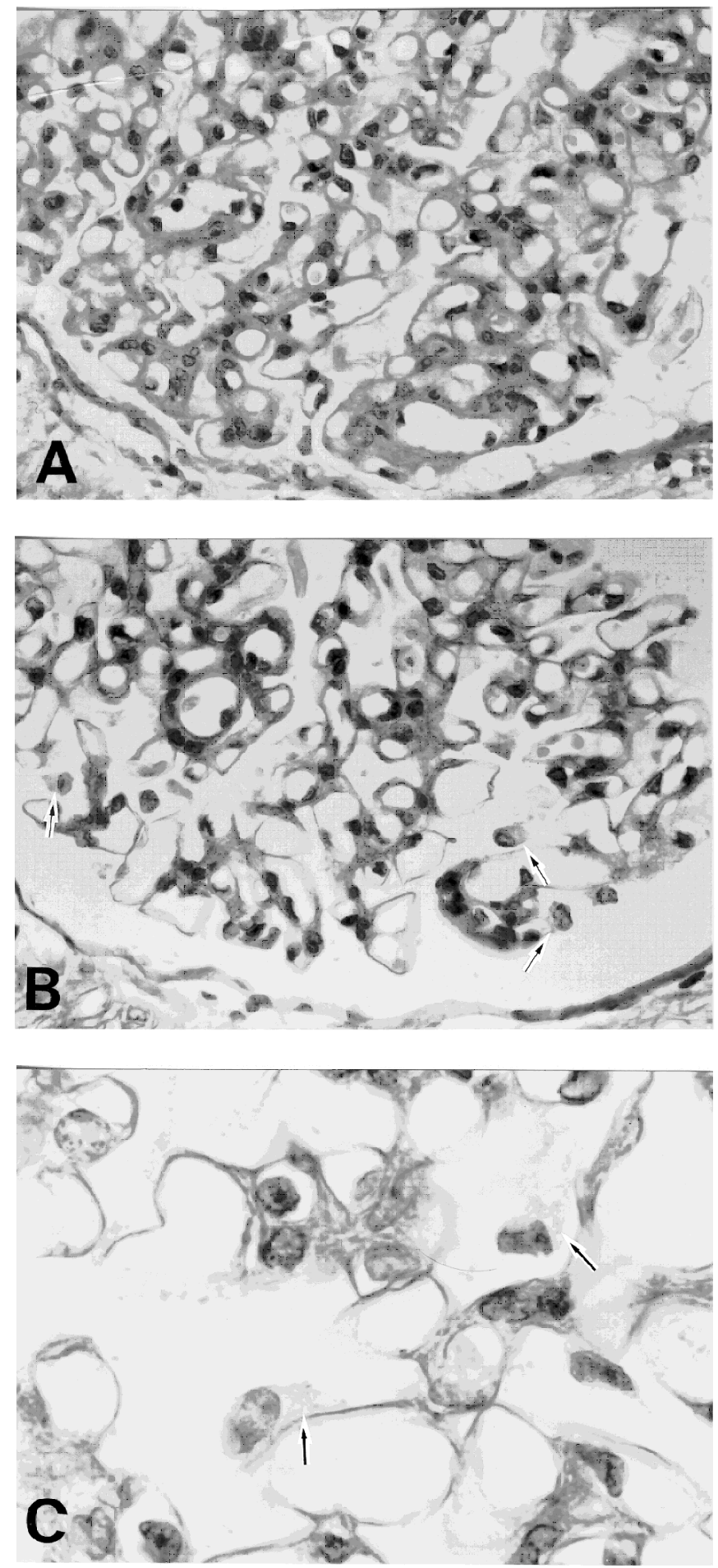

Fig. 2. In situ hybridization using $\alpha 1$ (VI) chain antisense oligo-DNA probe showing mRNA positive epithelial cells (arrow) in the diabetic glomeruli $(\mathrm{B}, \mathrm{C})$. Occasional mRNA positive mesangial cells, midst of PAS positive mesangial matrix are also noted. Adjacent section hybridized with sense probe disclosing no specific signals (A) (PAS counterstain). 


\subsection{Localization of $\alpha 1$ (VI) $m R N A$ by ISH}

It was found that occasionally glomerular epithelial cells and mesangial cells hybridized with Diglabeled antisense $\alpha 1$ (VI) oligo-DNA in normal kidney. In diabetic glomeruli, proportionally increased number of intraglomerular cells (mainly epithelial cells and infrequently mesangial cells) hybridized with Dig-labeled antisense pro $\alpha 1$ (VI) oligo-DNA (Fig. 2B and C). However, the numbers of $\alpha 1$ (VI) mRNA positive cells were decreased in advanced sclerotic glomeruli. Control experiments have established the specificity of the positive hybridization signals (Fig. 2A).

\section{Discussion}

Type VI collagen is an ubiquitous protein and its monomer consists of three distinct polypeptide chains, $\alpha 1$ (VI), $\alpha 2$ (VI) and $\alpha 3$ (VI) chains. In this study, utilizing non-radioactive ISH technique, we localized $\alpha 1$ (VI) mRNA in control and diseased glomeruli. The cells containing pro $\alpha 1$ (VI) chain mRNAs were identified in formalin-fixed paraffin-embedded renal biopsy specimens obtained from the patients of DN. ISH was done using a synthetic oligo-DNA complementary to mRNA of human pro $\alpha 1$ (VI) chain. Since it is rather difficult to distinguish mRNA-positive cell types in the glomeruli, which consist of mesangial, epithelial and endothelial cells, the specific intraglomerular type VI collagen mRNA-positive cell types was identified in renal sections by counterstaining with periodic acid schiff (PAS) after ISH [16]. In the renal biopsy sections of DN, the positive signals were predominantly found in the glomerular epithelial cells and occasionally in the mesangial cells.

Increased $\alpha 1$ (VI) mRNA positive cells and its protein in diabetic glomeruli reflected the overproduction of the type VI collagen in DN. Our results correlated with the findings of Mohan et al. [10], who using radioimmunoassay, reported 2.8-fold higher level of type VI collagen in human diabetic glomerular basement membrane preparations. Similarly, Nerlich et al. [12] showed increased immunostaining for type VI collagen in human diabetic glomerulosclerosis. Oomura et al. [13] also reported increased accumulation for various types of collagens including type VI collagen in human glomerular diseases.

In the current study, we were able to specify the type VI collagen synthesizing cells in DN, but the triggering factors for the increased synthesis of type VI collagen in diabetic glomeruli is not clear from this study. Experimental studies revealed that glomerular cells had the potential to produce different types of collagens in altered environment. Rat mesangial cells were able to produce interstitial collagens including type III collagen [1] and when cells were grown in a high glucose medium accumulated more fibronectin, laminin and type IV collagen than the cells grown in a low glucose medium [4]. The hyperglycemia elevates the levels of glomerular mRNAs that encode type IV collagen in the experimental diabetic kidneys [9]. When rat sciatic nerves were exposed to high glucose concentrations, it up-regulated the mRNA levels of $\alpha 1$ (VI), $\alpha 2$ (VI) and $\alpha 3$ (VI) chains of type VI collagen and caused accumulation of type VI collagen in the perineurial cells, Schwann cells, and fibroblasts [11]. In human DN, increased in situ expression of $\alpha 1$ chain mRNAs for type III and type IV collagens were noted in the mesangial and glomerular epithelial cells [16]. By comprising the above findings, it is likely that the hyperglycemic environment of DM might induced the excessive synthesis of type VI collagen similar to that of other components of ECM and might subsequently contribute to the sclerotic process in DN.

In conclusion, excessive synthesis of type VI collagen by intraglomerular cells (glomerular epithelial and mesangial cells) might contribute significantly to the glomerulosclerosis in diabetic nephropathy. 


\section{Acknowledgements}

We gratefully acknowledge the kind assistance of Ms. Y. Yamashita and Ms. S. Nakanose for preparing paraffin sections. Special thanks are due to Dr. M. Cheng and Dr. A. Nazneen for their technical assistance.

\section{References}

[1] C.K. Abrass, C.V. Peterson and G.J. Raugi, Phenotypic expression of collagen types in mesangial matrix of diabetic and non-diabetic rats, Diabetes 37 (1988), 1695-1702.

[2] J.C. Adams, Heavy metal intensification of DAB-based HRP reaction product, J. Histochem. Cytochem. 29 (1981), 775.

[3] A.R. Anderson, J.S. Christiansen, J.K. Anderson, S. Kreinen and K. Deckert, Diabetic nephropathy in type I (insulindependent) diabetes: An epidemiological study, Diabetologia 25 (1985), 496-501.

[4] S.H. Ayo, R.A. Radnik, W.F. Glass II, J.A. Garoni, E.R. Rampt, D.R. Appling and J.I. Kreisberg, Increased extracellular matrix synthesis and mRNA in mesangial cells grown in high glucose medium, Am. J. Physiol. 260 (1991), F185-F191.

[5] M.L. Chu, D. Conway, T.C. Pan, C. Baldwin, K. Mann, R. Deutzmann and R. Timpl, Amino acid sequence of triple-helical domain of human collagen type VI, J. Biol. Chem. 263 (1988), 18 601-18 606.

[6] J. Churg and L.H. Sobin, Renal Disease: Classification and Atlas of Glomerular Diseases, 1st edn, Igaku-Shoin, Tokyo, 1982, pp. 226-239.

[7] Y. Kim, M.M. Kleppel, R.J. Butkoski, S.M. Mauer, J. Wieslander and A.F. Michael, Differential expression of basement membrane collagen chains in diabetic nephropathy, Am. J. Pathol. 138 (1991), 413-420.

[8] T. Koji and R.M. Brenner, Localization of estrogen receptor messenger ribonucleic acid in rhesus monkey uterus by nonradioactive in situ hybridization with digoxigenin-labeled oligodeoxynucleotides, Endocrinology 132 (1993), 382-392.

[9] S. Ledbetter, E.J. Copeland, D. Noonam, G. Vogeli and J.R. Hassell, Altered steady-state mRNA levels of basement membrane proteins in diabetic mouse kidneys and thromboxane synthase inhibition, Diabetes 39 (1990), 196-203.

[10] P.S. Mohan, W.G. Carter and R.G. Spiro, Occurence of type VI collagen in extracellular matrix of renal glomeruli and its increase in diabetes, Diabetes 39 (1990), 31-37.

[11] P. Muona, S. Jaakkola, R.Z. Zhang, T.C. Pan, L. Pelliniemi, L. Risteli, M.L. Chu, J. Uitto and J. Peltonen, Hyperglycemic glucose concentrations up-regulate the expression of type VI collagen in vitro. Relevance to alterations of peripheral nerves in diabetes mellitus, Am. J. Pathol. 142 (1993), 1586-1597.

[12] A.G. Nerlich, E.D. Schleicher, I. Wiest, U. Specks and R. Timpl, Immunohistochemical localization of collagen VI in diabetic glomeruli, Kidney Int. 45 (1994), 1648-1656.

[13] A. Oomura, T. Nakamura, M. Arakawa, A. Ooshima and M. Isemura, Alteration of extracellular matrix components in human glomerular diseases, Virchows Arch. A (Pathol. Anat.) 415 (1989), 151-159.

[14] M.S. Razzaque, T. Koji, Y. Horita, M. Nishihara, T. Taguchi, T. Harada and P.K. Nakane, Synthesis of type III collagen and type IV collagen by tubular epithelial cells in diabetic nephropathy, Pathol. Res. Pract. 191 (1995), 1099-1104.

[15] M.S. Razzaque, T. Koji, H. Kawano, T. Harada, P.K. Nakane and T. Taguchi, Glomerular expression of type III and type IV collagens in benign nephrosclerosis: immunohistochemical and in situ hybridization study, Pathol. Res. Pract. 190 (1994), 493-499.

[16] M.S. Razzaque, T. Koji, T. Taguchi, T. Harada and P.K. Nakane, In situ localization of type III and type IV collagen expressing cells in human diabetic nephropathy, J. Pathol. 174 (1994), 131-138.

[17] M.S. Razzaque and T. Taguchi, Expression of type III collagen mRNA in renal biopsy specimens of patients with idiopathic membranous glomerulonephritis, J. Clin. Pathol. (Mol. Pathol.) 49 (1996), M40-M42. 


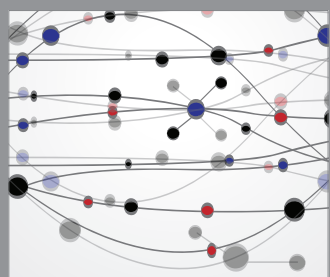

The Scientific World Journal
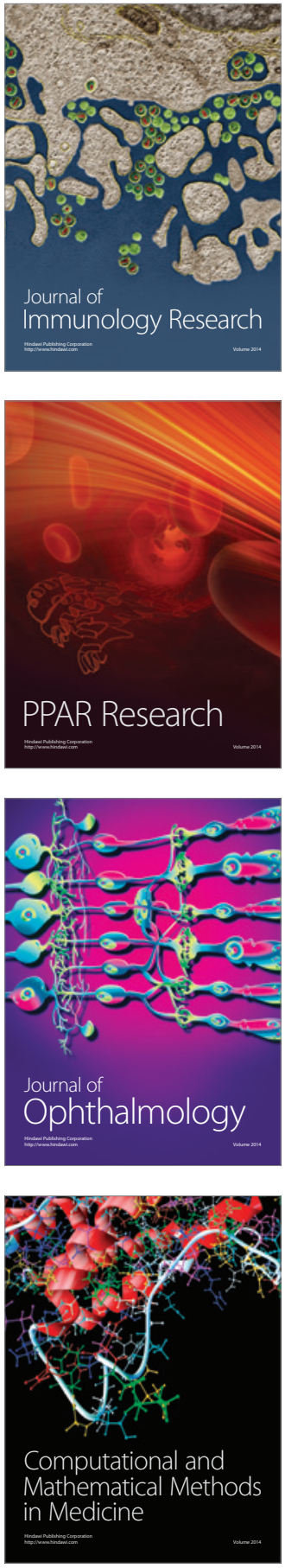

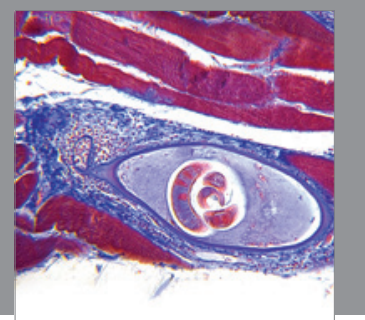

Gastroenterology

Research and Practice
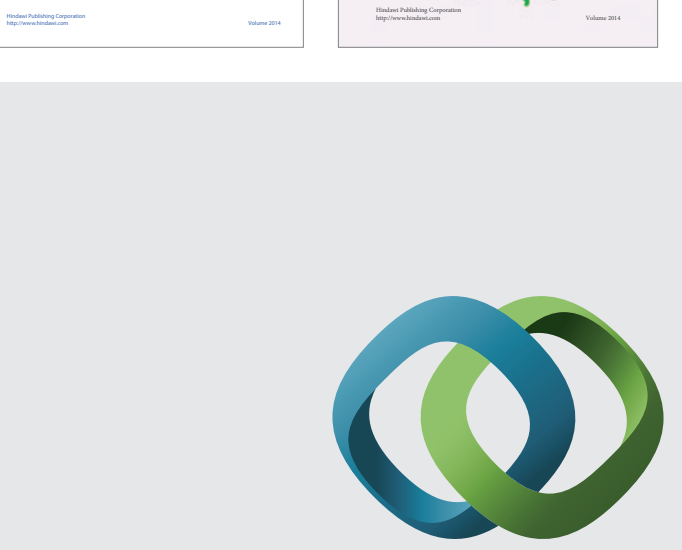

\section{Hindawi}

Submit your manuscripts at

http://www.hindawi.com
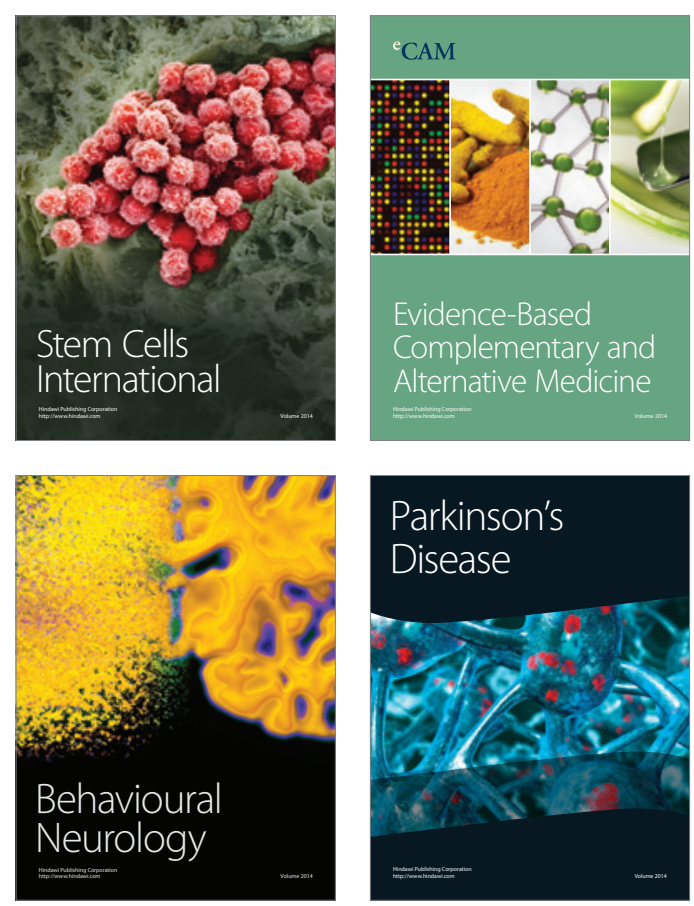

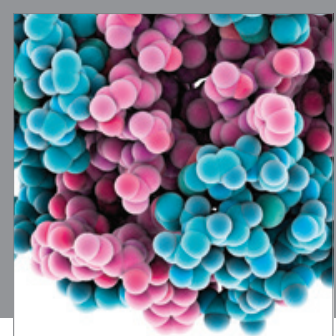

Journal of
Diabetes Research

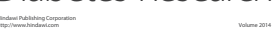

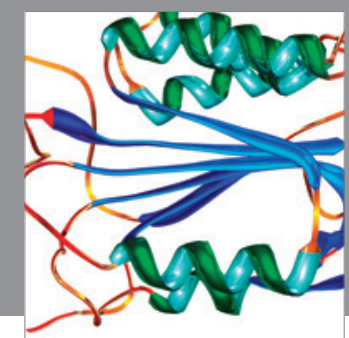

Disease Markers
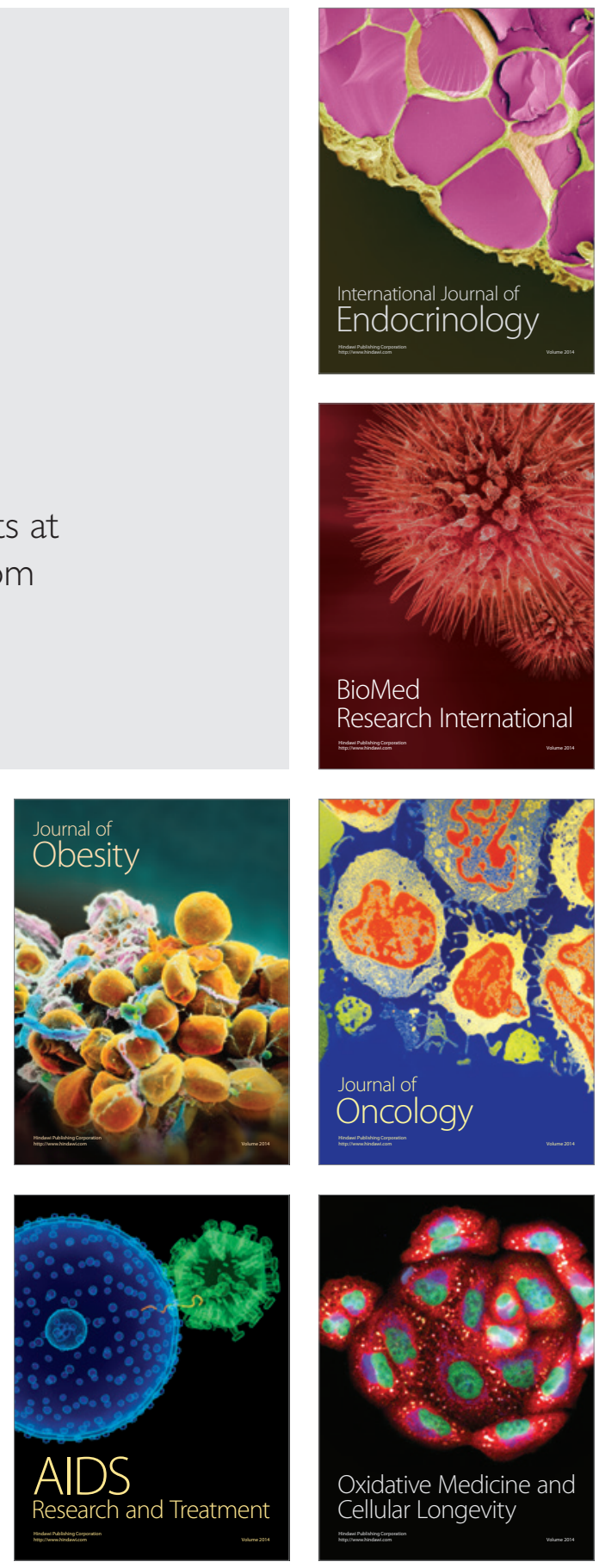